\title{
LATIHAN METODE DRIL TERHADAP KETEPATAN JUMP SERVICE PADA ATLET BOLA VOLI PUTERA
}

\section{DRIL METHOD OF EXERCISE ON THE ACCURACY OF JUMP SERVICE AT THE ATTRACTION VOLLEY}

\author{
Resa Sukardi Massa \\ Jurusan Pendidikan Kepelatihan Olahraga, Fakultas Olahraga dan Kesehatan, \\ Univeristas Negeri Gorontalo \\ Kontak Penulis: resasetter@gmail.com
}

\begin{abstract}
ABSTRAK
Banyak sekali metode latihan yang bisa digunakan dalam cabang olahraga. Salah satu metode yang bisa digunakan adalah metode dril. Tujuan dari artikel penelitian adalah untuk mengetahui pengaruh metode dril terhadap ketepatan jump service pada atlet bola voli putera FIKK UNG. Metode yang digunakan dalam penelitian ini adalah metode eksperimen. Untuk menguji hipotesis yang menyatakan bahwa terdapat pengaruh metode dril terhadap ketepatan jump service pada atlet bola voli putera FIKK UNG dugunakan teknik statistik uji t analisa varians (ANAVA). Hasil dari penelitian ini bahwa terdapat pengaruh yang baik dengan menggunakan metode dril terhadap ketepatan jump service pada atlet bola voli putera FIKK UNG. Metode dril akan dapat melatih atlet bola voli untuk terbiasa dengan melakukan pengulangan jump service, sehingga ketepatan akurasinya akan meningkat seiring dengan keterlatihan dari metode dril ini.
\end{abstract}

Kata kunci: metode dril; jump service; atlet bola voli

\begin{abstract}
ABSTRAC
There are so many training methods that can be used in sports. One method that can be used is the Dril method. The purpose of the research article was to determine the effect of the dril method on the accuracy of the jump service in the FIKK UNG male volleyball athlete. The method used in this research is the experimental method. To test the hypothesis which states that there is an effect of the dril method on the accuracy of jump service in the male volleyball athlete FIKK UNG is used statistical analysis t-test analysis of variance (ANOVA). The results of this study that there is a good influence by using the dril method on the accuracy of the jump service in FIKK UNG male volleyball athletes. Draft methods will be able to train volleyball athletes to get used to doing the jump service repetition so that the accuracy of the accuracy will increase along with the training of this draft method.
\end{abstract}

Keywords: Dril; accuracy; volleyball athletes 


\section{PENDAHULUAN}

Upaya untuk mengembangkan olahraga bola voli di Provinsi Gorontalo, Universitas Negeri Gorontalo, khususnya Fakultas Ilmu-ilmu Kesehatan dan Keolahragaan telah membentuk tim bola voli putra sebagai wadah untuk dapat menyalurkan minat dan bakat serta berprestasi pada cabang olahraga ini. Sejak terbentuknya tim bola voli pada Oktober 2011, FIKK UNG mulai membina atlet-atlet muda bola voli yang mampu berprestasi dan juga di persiapkan untuk kejuaraankejuaraan di tingkat nasional nanti.

Permainan bola voli adalah suatu permainan yang menggunakan bola untuk di Volley (dipantulkan) di udara hilir mudik di atas net (Jaring) dengan maksud dapat menjatuhkan bola di dalam petak daerah lapangan lawan, dalam rangka mencari kemenangan. Mem-volley atau memantulkan bola ke udara dapat dipergunakan seluruh anggota atau bagian tubuh dari ujung kaki sampai ke kepala dengan pantulan sempurna. (Mukholid, 2004).

Bola voli adalah permainan yang dilakukan oleh dua regu, yang masing-masing terdiri dari 6 orang. Bola dimainkan di udara dengan melewati net, setiap regu hanya bisa memainkan bola tiga kali pukulan. "Permainan bola voli adalah olahraga beregu tetapi kemahiran individu sangatlah penting untuk memudahkan kerjasama yang baik dalam mencapai hasil yang maksimal".

Tujuan utama dari setiap tim atau regu adalah memukul bola kearah bidang lapangan lawan sedemikian rupa agar lawan tidak dapat mengembalikan bola (Viera Dkk, 2004). Tujuan lain yang dikatakan oleh Muhajir (2007) bahwa "Tujuan permainan bola voli adalah memperagakan teknik dan taktik memainkan bola di lapangan untuk meraih kemenangan dalam setiap pertandingan. Selanjutnya di tambahkan bahwa teknik dasar memiankan bola voli yang harus ditingkatkan keterampilanya adalah Passing bawah, passing atas, smash, spike, service dan bendungan (Block).

Untuk mencapai suatu prestasi atau hasil yang maksimal pada permainan bola voli diperlukan teknik-teknik bermaian. Teknik bermain bola voli berhubungan erat dengan kondisi fisik, taktik dan mental. Oleh karena itu para pemain terlebih dahulu harus menguasai teknik dasar, agar mutu prestasi permainan dapat di kembangkan. Hasil maksimal yang belum dapat dicapai, tentunya merupakan suatu kelemahan baik pada saat latihan maupun pertandingan. Melalui pengamatan penulis dari beberapa kejuaraan daerah, salah satu kelemahan yang nampak adalah kurang sempurnanya melakukan service khususnya jump-service, yang memiliki tingkat kesulitan yang tinggi, sehingga serangan awal yang dilakukan melalui jump-service, bola sering menyangkut net dan keluar lapangan pertandingan atau kurang terarah yang pada akhirnya menguntungkan pihak lawan.

Servis adalah bentuk serangan pertama, maka dalam melakukannya harus penuh konsentrasi dan adanya keinginan untuk membuat angka hanya pada servis saja (PBVSI, 2011). pentingnya kedudukan service dalam permainan bola voli, karena service dengan jenis jump service, akan menghasilkan pukulan service yang menukik dengan tajam dan keras sehingga dapat menimbulkan kesulitan bagi tim lawan penerima service. Oleh karena itu service harus keras dan terarah dengan tujuan agar tidak mudah diterima oleh lawan yang berarti pihak pemegang service mendapatkan poin.

Jumping service merupakan teknik dasar dalam permainan bola voli yang sulit dilakukan, karena mempunyai gerakan yang kompleks. Gerakan itu terdiri dari unsur loncatan, kekuatan dan kecepatan. Kesalahan yang sering terjadi atau yang dilakukan oleh pemain adalah tidak adanya kekuatan loncatan atau daya ledak secara maksimal. Dalam melakukan gerakan jumping service kekuatan loncatan yang diwujudkan dalam daya ledak sangat mempengaruhi hasil service. Sedangakan kekuatan dan kecepatan tangan untuk memukul bola agar laju bola cepat dan keras tepat pada sasaran, karena dengan loncatan dan raihan yang tinggi akan mempermudah 
pelaksanaan service. Pemain yang mempunyai kekuatan loncatan dan daya ledak maksimal, maka waktu diudara akan lebih lama, sehingga seorang pemain akan lebih mudah dalam melakukan jumping service. Servis adalah bentuk serangan pertama, maka dalam melakukannya harus penuh konsentrasi dan adanya keinginan untuk membuat angka hanya pada servis saja (PBVSI, 2011).

Dalam permainan bola voli dikenal istilah jumping yaitu sikap meloncat waktu melakukan gerakan smash, yang maksudnya adalah bergerak kearah yang lebih tinggi atau vertikal, waktu melakukan gerakan jumping service yang dapat dilakukan bila seseorang mempunyai strength dan power atau daya ledak pada otot tungkai dan selanjutnya daya ledak otot lengan yang mengenai bola sangat menentukan kecepatan, kekuatan laju bola serta ketepatannya menuju arah yang dituju pemain bola voli yang melakukan jumping service.

Dalam buku Sudjana, (2012) metode dril adalah "satu kegiatan melakukan hal yang sama, berulang-ulang secara sungguh-sungguh dengan tujuan untuk memperkuat suatu asosiasi atau menyempurnakan suatu ketrampilan agar menjadi bersifat permanen. Dalam hal ini latihan jump service bola voli dilakukan dengan metode dril yaitu, metode latihan dengan memilah-milah teknik gerakan jump service. Artinya latihan jump service yaitu dengan melakukan gerakan teknik-teknik jump service secara berulang-ulang. Berkaitan dengan metode dril Sagala, (2009) "Metode dril adalah metode latihan, atau metode training yang merupakan suatu cara mengajar yang baik untuk menanamkan kebiasaan-kebiasaan tertentu, juga sebagai sarana untuk memperoleh suatu ketangkasan, ketepatan, kesempatan dan keterampilan.

Secara umum penelitian ini bertujuan untuk pengembangan ilmu keolahragaan, dan meningkatkan serta mengembangkan kualitas pelatihan dalam memecahkan masalah-masalah dalam pelatihan untuk mencapai prestasi optimal. Sedangkan secara khusus, penelitian ini bertujuan untuk mengkaji apakah terdapat pengaruh metode dril terhadap ketepatan jump service pada atlet bola voli putra FIKK UNG.

\section{METODE PENELITIAN}

Penelitian ini dilaksanakan di lapangan FIKK UNG. Waktu pelaksanaan penelitian dilakukan selama 2 bulan. Penelitian ini bertujuan untuk mengetahui apakah terdapat pengaruh metode dril terhadap peningkatan ketepatan jump service pada atlet bola voli putra FIKK UNG. Jenis penelitian ini adalah penelitian eksperimen dengan menggunakan One Group Pretest-Posttest Design. Populasi dalam penelitian ini adalah atlet bola voli putra FIKK UNG yang berjumlah 11 orang. Mengacu pada desain penelitian di atas, maka populasi di atas akan dijadikan anggota sampel secara keseluruhan, dengan kata lain penelitian ini merupakan penelitian populasi.

\section{HASIL DAN PEMBAHASAN}

Dari hasil pengukuran diperoleh data ketepatan jump service baik pre-test dan post-test. Data tersebut tertuang dalam tabel sebagai berikut:

Tabel 1. Data hasil jump service

\begin{tabular}{ccc}
\hline NO & $\begin{array}{c}\text { Pre-Test } \\
\left(\mathbf{X}_{\mathbf{1}}\right)\end{array}$ & $\begin{array}{c}\text { Post-Test } \\
\left(\mathbf{X}_{\mathbf{2}}\right)\end{array}$ \\
\hline 1 & 24 & 33 \\
\hline 2 & 19 & 33 \\
\hline 3 & 12 & 47 \\
\hline 4 & 17 & 28 \\
\hline 5 & 21 & 33 \\
\hline
\end{tabular}




\begin{tabular}{ccc}
\hline 6 & 12 & 26 \\
\hline 7 & 13 & 28 \\
\hline 8 & 9 & 18 \\
\hline 9 & 15 & 26 \\
\hline 10 & 11 & 26 \\
\hline 11 & 8 & 16 \\
\hline
\end{tabular}

Dilihat dari pengukuran besaran-besaran statistik diatas dapat diartikan bahwa, ada peningkatan ketepatan jump service atlet bola voli FIKK UNG. Hal ini dapat dilihat dari peningkatan rata-rata sebelum diberikan latihan dril sebesar 161 dan sesudah diberikan latihan dril sebesar 314. Oleh karena itu peneliti berasumsi bahwa pemberian latihan dril, memberikan pengaruh terhadap ketepatan jump service pada atlet bola voli FIKK UNG.

Seorang pemain bola voli harus mempunyai komponen kondisi fisik yang dominan yaitu; komponen daya ledak, komponen kekuatan, komponen kelentukan, kompenen kelincahan, komponen reaksi, dan komponen ketepatan. Dalam usaha untuk meningkatkan komponenkomponen fisik tersebut sangatlah dipengaruhi oleh sekian banyak faktor sehingga benar-benar diperlukan ketepatan untuk dapat mengaplikasikan pendekatan secara ilmiah sesuai dengan disiplin ilmu.

Penelitian dengan metode eksperimen ini dimaksud untuk mengukur dan memperoleh gambaran tentang pengaruh metode dril terhadap ketepatan jump service pada atlet bola voli putra FIKK UNG. Berdasarkan hasil eksperimen yang telah dianalisis dengan pengujian statistik, menunjukan bahwa adanya peningkatan ketepatan jump service yang signifikan setelah dilakukan eksperimen atau latihan dril tersebut.

\section{SIMPULAN DAN SARAN}

Berdasarkan hasil analisis dan pembahasan yang telah diuraikan pada tulisan sebelumnya, maka hasil penelitian yang dilakukan selama dua bulan dapat disimpulkan bahwa metode dril memberikan dampak yang signifikan terhadap peningkatan ketepatan dalam melakukan jump service pada cabang olahraga bola voli sehingga dalam rangka memacu seorang atlet bola voli dalam usaha untuk meningkatkan ketepatan keterampilanya khususnya ketepatan jump service, maka sangat efektif diterapkanya metode dril atau latihan dril dalam merencanakan program latihan

\section{REFERENSI}

Muhajir. (2007) Pendidikan Jasmani Olahraga dan Kesehatan 3, Jakarta: Erlangga Mukholid, A. (2004). Pendidikan Jasmani dan Olahraga. Jakarta: Yudistira PBVSI. (2011). Penataran Pelatih Nasional Bola Voli. Jakarta: PBVSI

Sagala, S. (2009). Metode Dril. Tersedia di: http://dianiveby.blogspot.com. (23 April 2012) Sudjana, N. (2012). Penilaian Hasil Proses Belajar Mengajar. Bandung: Remaja Rosdakarya Vera, B.L. (2004). Bola Voli Tingkat Pemula. Jakarta: PT Rajagrafindo Persada 